\title{
Structure-properties relationships in melt reprocessed PLA/hydrotalcites nanocomposites
}

\author{
R. Scaffaro", F. Sutera, M. C. Mistretta, L. Botta, F. P. La Mantia \\ Dipartimento di Ingegneria Civile, Ambientale, Aerospaziale, dei Materiali, Università di Palermo, UdR INSTM di \\ Palermo, Viale delle Scienze, 90128 Palermo, Italy
}

Received 25 November 2016; accepted in revised form 10 February 2017

\begin{abstract}
In this work the effect of multiple reprocessing was studied on molecular structure, morphology and properties of poly(lactic acid)/hydrotalcites (PLA/HT) nanocomposites compared to neat PLA. In addition, the influence of two different kinds of HT - organically modified (OM-HT) and unmodified (U-HT) - was evaluated. Thermo-mechanical degradation was induced by means of five subsequent extrusion cycles. The performance of the recycled materials was investigated by mechanical and rheological tests, differential scanning calorimetry (DSC), intrinsic viscosity measurements and SEM observation.

The results indicated that the best morphology was achieved in the systems incorporating OM-HT. On increasing the extrusion reprocessing cycles, the properties showed behavior due to two opposite effects: i) chain scission due to thermo-mechanical degradation and ii) filler dispersion effect resulting from multiple processing. In particular, at low reprocessing cycles, both tensile and rheological properties seem to be mainly affected by HT dispersion, especially when OM-HT was added. After five reprocessing cycles, on the contrary, chain scission, i.e. thermo-mechanical degradation, dominated.

As regards the effect of the presence of organic modifier in HT, the results indicated that this variable apparently did not affect the macroscopic performance of the nanocomposites, especially at high reprocessing cycles.
\end{abstract}

Keywords: recycling, nanocomposites, PLA, hydrotalcites, melt processing

\section{Introduction}

In the last few decades, in order to minimize waste and environmental pollution, both the scientific community and the industries have widely paid attention to recycling oil-derived polymers $[1,2]$. Besides recycling, the use of biodegradable polymers is rising as an alternative solution [3, 4]. However, the replacement of conventional polymers with biodegradable polymers cannot be the only way to reduce the accumulation of plastic materials in landfills. Several papers also investigated the possibility to recycle biodegradable polymers in order to reduce the environmental impact related to the life cycle of biodegradable polymer-based items [5-11]. Among the different recycling routes, mechanical reprocessing represent an easy and low cost method [12, 13]. Among biodegradable polymers, poly(lactic acid) (PLA) gained much attention thanks to its interesting properties including good processability, mechanical properties and performance, making it a good candidate for replacing commodities, e.g. in food packaging. Recently, polymer nanocomposites, have received a great interest because they exhibit good mechanical, thermal and barrier properties [14, 15]. Due to the growing market of nanocomposites, the scientific literature has currently studied the effect of reprocessing of the nanocomposites based on conventional polymers [13, 16-19]. Moreover, several studies investigated the effect of the reprocessing on the properties of neat biodegradable polymers, such 
as PLA $[5,6,8,20]$. However, recycling of PLA-based biodegradable nanocomposites was not been investigated in depth so far.

PLA is susceptible to thermo-degradation during melt processing operations [20, 21]. For this purpose, the study of thermo-mechanical degradative phenomena associated to its re-processing [20, 22, 23 ] is of great concern in order to assess the possibility of recycling PLA-based nanocomposites. To enhance some properties of PLA, such as mechanical and gas barrier properties and to extend its use in food packaging applications, small amounts of nanoparticles can be loaded in the matrix [24]. For this purpose, in this work, we used hydrotalcites (HT) as nanofiller. HT consist of positively charged brucite-like infinite layers, where trivalent cations replace a fraction of the bivalent cations in octahedral coordination. The positive charge of the layers is balanced by intercalated hydrated anions [25]. Unmodified HT, as well as commercial or ad hoc modified HT, have been extensively used as filler for PLA based nanocomposites [26-31]. Nevertheless, to the best of our knowledge no work investigated how the reprocessing affects the properties of PLA/HT nanocomposites.

This work aims to evaluate the effect of reprocessing on molecular structure, morphology and properties of PLA reinforced with HT compared to the neat polymeric matrix. For this purpose, mechanical recycling was carried out by means of five subsequent extrusion cycles. Two different types of HT - organically modified (OM-HT) and unmodified (U-HT) - were used. Scanning electron microscopy (SEM), intrinsic viscosity measurements, thermal, rheological and mechanical tests are performed on the reprocessed materials.

\section{Experimental}

\subsection{Materials}

PLA (Ingeo ${ }^{\mathrm{TM}}$ Biopolymer 4032D, NatureWorks, Minnetonka, Minn., USA) is an extrusion grade with melt flow rate (MFR) of $7 \mathrm{~g} / 10 \mathrm{~min}\left(210^{\circ} \mathrm{C}, 2.16 \mathrm{~kg}\right)$, density of $1.24 \mathrm{~g} / \mathrm{cm}^{3}$ and melting point of $155-$ $170^{\circ} \mathrm{C}$.

The nanofillers are two commercial samples of HT. The first is an unmodified hydrotalcite (U-HT) (Perkalite LD, Akzo Nobel, Amsterdam, The Netherlands), the second is organically modified with hydrogenated fat acids (OM-HT) (Perkalite F100S,
Akzo Nobel, Amsterdam, The Netherlands, modifier content $=55 \mathrm{wt} \%$ ).

In a previous work [32], OM-HT was characterized by Fourier transform infrared spectroscopy (FT-IR) and thermogravimetric analysis (TGA) and it was shown that it is most likely modified with stearate and palmitate anions and the amount of adsorbed/free surfactant molecules is low (roughly $3 \mathrm{wt} \%$ ).

Tetrahydrofuran (THF) is purchased by Sigma Aldrich (St. Louis, USA).

\subsection{Materials preparation}

\subsubsection{Nanocomposites preparation}

Nanocomposites (containing $5 \mathrm{wt} \%$ of filler) were prepared in a co-rotating twin-screw extruder (type EBV 19/35 D, OMC, Saronno, Italy). Mechanically mixed polymer pellets and HT were poured inside the feeder at a rotational speed of $16 \mathrm{rpm}$ and processed at a screw rotational speed of $220 \mathrm{rpm}$. The extruder temperature profile adopted was 180-190-190-200200-200-190 ${ }^{\circ} \mathrm{C}$. For comparison, neat PLA was processed under the same conditions adopted for the nanocomposites. Then, the obtained materials were pelletized for further characterization and/or reprocessing.

In order to prevent possible hydrolytic scission of the matrix during processing, both PLA and HT were preventively dried overnight under vacuum at 90 and $110^{\circ} \mathrm{C}$, respectively.

\subsubsection{Reprocessing}

Reprocessing was carried out using a single screw extruder (Thermo Scientific HAAKE PolyLab QC, Karlsruhe, Germany) up to five subsequent extrusion cycles. The temperature profile was set to 180-190$200-190^{\circ} \mathrm{C}$ while the screw rotational speed was $50 \mathrm{rpm}$. For comparison, reprocessing was carried out both on PLA nanocomposites and on neat PLA under the same conditions. Before each step, the materials were dried overnight under vacuum at $90^{\circ} \mathrm{C}$, in order to prevent phenomena of hydrolytic chain scission. The molten material coming out from the extruder die was cooled in air and afterwards pelletized to be used for further characterizations. After each further extrusion process, an amount of the material was kept for analysis. The sample codes, the compositions and the reprocessing step of all the investigated materials are reported in Table 1. 
Table 1. Sample code, composition and reprocessing step of all the materials investigated in this work

\begin{tabular}{|l|r|c|c|c|}
\hline \multicolumn{1}{|c|}{ Code sample } & $\begin{array}{c}\text { PLA } \\
{[\mathbf{w t \%}]}\end{array}$ & $\begin{array}{c}\text { OM-HT } \\
{[\mathbf{w t} \%]}\end{array}$ & $\begin{array}{c}\text { U-HT } \\
{[\mathbf{w t} \%]}\end{array}$ & Processing \\
\hline PLA R0 & 100 & - & - & Extrusion \\
\hline PLA R1 & 100 & - & - & Recycle-1 \\
\hline PLA R3 & 100 & - & - & Recycle-3 \\
\hline PLA R5 & 100 & - & - & Recycle-5 \\
\hline PLA + OM-HT R0 & 95 & 5 & - & Extrusion \\
\hline PLA+ OM-HT R1 & 95 & 5 & - & Recycle-1 \\
\hline PLA+ OM-HT R3 & 95 & 5 & - & Recycle-3 \\
\hline PLA+ OM-HT R5 & 95 & 5 & - & Recycle-5 \\
\hline PLA + U-HT R0 & 95 & - & 5 & Extrusion \\
\hline PLA + U-HT R1 & 95 & - & 5 & Recycle-1 \\
\hline PLA + U-HT R3 & 95 & - & 5 & Recycle-3 \\
\hline PLA + U-HT R5 & 95 & - & 5 & Recycle-5 \\
\hline
\end{tabular}

\subsection{Characterizations}

\section{Scanning Electron Microscopy (SEM)}

The morphology of the extruded nanocomposites was analyzed by scanning electron microscopy (Quanta 200 ESEM, FEI, Hillsboro, Oregon USA). Images were taken in secondary electron imaging mode by using an accelerating voltage of $10.0 \mathrm{kV}$, spot size 4 at a working distance of $12 \mathrm{~mm}$. Each sample was fractured in liquid nitrogen and then sputter-coated with a thin layer of gold under argon atmosphere for 120 s (Scancoat Six, Edwards, Crawley, United Kingdom.) in order to avoid electrostatic charging during the analysis. Considering that under the used conditions the sputter coater deposition is about $8 / 9 \mathrm{~nm} / \mathrm{min}$, the estimated thickness of sputtered gold layer is about $17 \mathrm{~nm}$.

\section{Rheological properties}

The rheological characterization was performed using a plate-plate rotational rheometer (HAAKE MARS, Thermo Scientific, Waltham, MA, USA), operating at $190^{\circ} \mathrm{C}$. The instrument has been set to operate in frequency sweep mode in the range $0.1-500 \mathrm{rad} / \mathrm{s}$ with a strain of $5 \%$. Before testing, the samples were vacuum dried overnight at $90^{\circ} \mathrm{C}$.

Specimens for rheological characterizations were obtained by compression molding at $190^{\circ} \mathrm{C}$ and 100 bar using a Carver (Wabash, IN, USA.) laboratory press.

\section{Differential scanning calorimetry}

Thermal properties of the processed materials were studied using a differential scanning calorimeter (Perkin Elmer DSC 7, Waltham, MA, USA). The experiments were performed under $\mathrm{N}_{2}$ gas flow
(20 $\mathrm{mL} / \mathrm{min})$. Samples underwent a heating/cooling/heating program in the temperature range 30 $200^{\circ} \mathrm{C}$. The heating rate was $10^{\circ} \mathrm{C} / \mathrm{min}$ and the cooling rate was $40{ }^{\circ} \mathrm{C} / \mathrm{min}$.

The crystallinity $(\chi)$ of PLA and its nanocomposites was calculated by Equation (1):

$\chi=\frac{\Delta H_{\mathrm{m}}-\Delta H_{\mathrm{cc}}}{\Delta H_{\mathrm{m}}^{0}} \cdot 100$

where $\Delta H_{\mathrm{m}}$ and $\Delta H_{\mathrm{cc}}$ are, respectively, the melting enthalpy and the cold crystallization enthalpy of the sample; $\Delta H_{\mathrm{m}}^{0}$ is the melting enthalpy of $100 \%$ crystalline PLA (93.7 J/g) [33].

Enthalpy values found for nanocomposites were normalized on the actual amount of polymer involved in the thermal transition, being hydrotalcites not involved in melting/crystallization processes.

\section{Mechanical properties}

Tensile tests of the processed materials were carried out using a universal testing machine (Instron model 3365, Torino, Italy). The specimens (rectangular shaped $90 \times 10 \mathrm{~mm}$ ) were cut off from sheets (thickness about $0.5 \mathrm{~mm}$ ) obtained by compression molding at $190^{\circ} \mathrm{C}$ and 100 bar using a Carver (Wabash, IN, USA) laboratory press. The initial crosshead speed was $1 \mathrm{~mm} / \mathrm{min}$. When the displacement was $1 \mathrm{~mm}$, the crosshead speed was increased to $10 \mathrm{~mm} / \mathrm{min}$ until break. A minimum of 7 specimens were averaged for each material.

\section{Viscometry}

The intrinsic viscosity [ $\eta$ ] was measured by means of a iVisc Capillary Viscometer LMV 830 (Lauda Proline PV 15, Lauda-Königshofen, Germany) instrument equipped with a Ubbelohde $(K=0.009676)$ capillary viscometer in an oil bath thermostated at $35^{\circ} \mathrm{C}$.

In order to prepare the solution at the concentration of $0.2 \mathrm{wt} \%$, each material was dissolved in THF under stirring at $50^{\circ} \mathrm{C}$ for 1 hour.

Flow time measurements were performed in triplicate for each sample until the standard deviation was below $0.5 \mathrm{~s}$.

The intrinsic viscosity values was calculated according to Solomom-Ciuta by Equation (2) [34]:

$[\eta]=\frac{\sqrt{2}}{c} \sqrt{\eta_{\mathrm{sp}}-\ln \eta_{\mathrm{rel}}}$

where $c$ is the concentration of the polymer solution, $\eta, \eta_{\text {sp }}$ and $\eta_{\text {rel }}$ are, respectively, intrinsic, specific and 
relative viscosity. The solution viscosity of each sample was obtained by averaging 5 flow measurements. The viscosimetric molecular weight $\left(M_{\mathrm{v}}\right)$ was calculated using the Mark-Houwink's equation (Equation (3)):

$$
[\eta]=K M_{\mathrm{v}}^{\mathrm{a}}
$$

The parameter values of the Mark-Houwink constants, $a$ and $K$, depend upon the specific polymersolvent system. For PLA-THF, $K=1.74 \cdot 10^{-4}$ and $a=$ 0.736 [35].

\section{Results and discussion}

Figure 1 display SEM micrographs of PLA/HT nanocomposites. It is worth noting that all the micrographs show the presence of many cracks on the sample surfaces. This drawback can be very probably attributed to the sensitivity of PLA to electron beam that damaged the polymer surface of the samples during the SEM examination [36]. The samples filled with the OM-HT (Figures 1a-1c) show a higher level of particle dispersion and a lower presence of aggregates if compared with those of the materials containing U-HT, (Figures 1d, 1e), regardless of the extrusion number. In particular, PLA + OM-HT samples (Figures 1a-1c) exhibit good dispersion of the filler, reduction and uniformity in size, and optimal adhesion between the matrix and the hydrotalcite, as already reported in our previous work [27]. On the contrary, the materials filled with U-HT (Figures 1d-1e) exhibit the simultaneous presence of dispersed particles and fairly large aggregates and a weak adhesion between the particles and the polymer. Comparing PLA + OM-HT R0 (Figure 1a) with PLA + OMHT R1 (Figure 1b) and R5 (Figure 1c) it is worth noting a reduction of the particle size and an improved dispersion as a function of the number of reprocessing. This improvement can be related to longer residence time of the material in the extruder during the reprocessing in which high levels of strain applied to the melt promote enhanced mixing of the dispersed phase $[17,18]$.

SEM micrograph of PLA + U-HT R5 (Figure 1e) reveals a damaged polymer matrix in comparison to that of PLA + U-HT R0 (Figure 1d). In particular, surface modifications, worsening in the adhesion between U-HT and the matrix and holes around the particles can be observed.
The complex viscosity as a function of frequency is reported in Figure 2 for all the systems presented in this work. The rheological curves of not reprocessed materials (Figure 2a) reveal that the viscosity of the nanocomposites is lower than the viscosity exhibited by the neat matrix in the whole frequency range. This behavior, which might be surprizing, is in agreement with previous work [27]. At low frequencies, neat PLA exhibits a Newtonian plateau not present in the nanocomposites (Figure 2a). The non-Newtonian behaviour of nanocomposites at the lowest frequencies can be explained considering a solid-like behaviour of the material induced by three-dimensional structures typical of nanofilled systems [37]. The formation of this three-dimensional percolated network is due to the polymer-filler interactions that offer a resistance to the flow [37-39]. When the shear rate is higher, this structures are disrupted and the nanocomposites behave as a suspension of nanoparticles in a melt matrix [40].

After the subsequent extrusion steps, the viscosity of PLA decreases likely due to polymer chain degradation (Figure 2b). The scientific literature reports three possible hypotheses for explaining degradation phenomena of the matrix occurring during processing: i) radical degradation, ii) hydrolysis and/or iii) transesterification with residual catalysts [41]. PLA + U-HT nanocomposites (Figure 2d) show the same trend as PLA as a function of reprocessing cycles. Moreover, for each reprocessing cycle, PLA + UHT nanocomposites exhibit a lower viscosity in comparison to the respective reprocessed matrix. Chain scission promoted by the presence of U-HT can be invoked to explain this behaviour [27]. Surprisingly, this trend does not occur for PLA incorporating OMHT (Figure 2c), in which the value of viscosity increased after the first recycle. This result can be explained considering that the first reprocessing leads to a better dispersion of the filler, as shown by SEM micrographs, that likely overcomes the thermo-degradation phenomena occurring during reprocessing. Afterwards, from the third recycle, the effect of degradation phenomena is predominant over the dispersion effect and the values of the complex viscosity decrease (Figure 2c). For PLA + OM-HT the decrease of viscosity due to reprocessing is more remarkable in comparison to the PLA + U-HT likely because of the strong interactions between the organically-modified hydrotalcite and the polymer matrix 


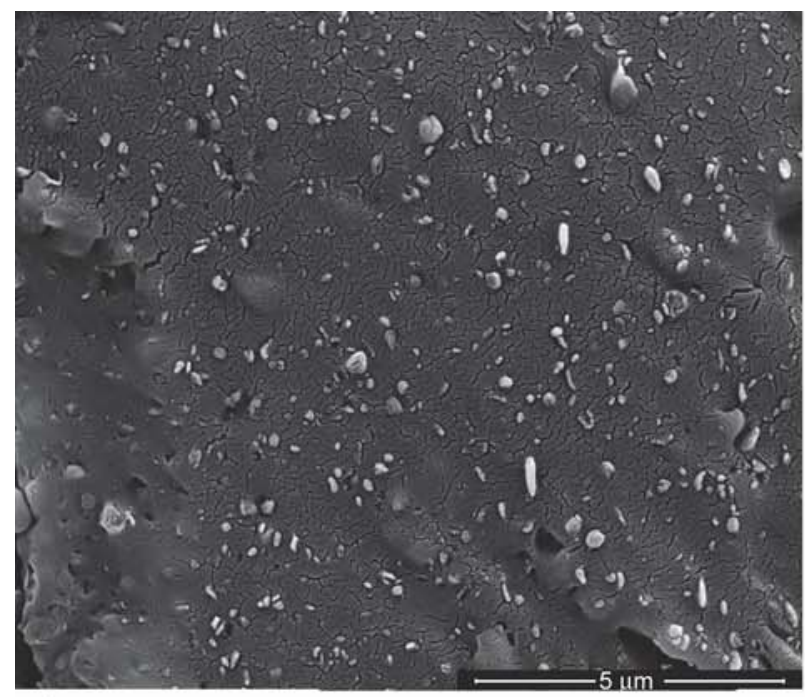

a)

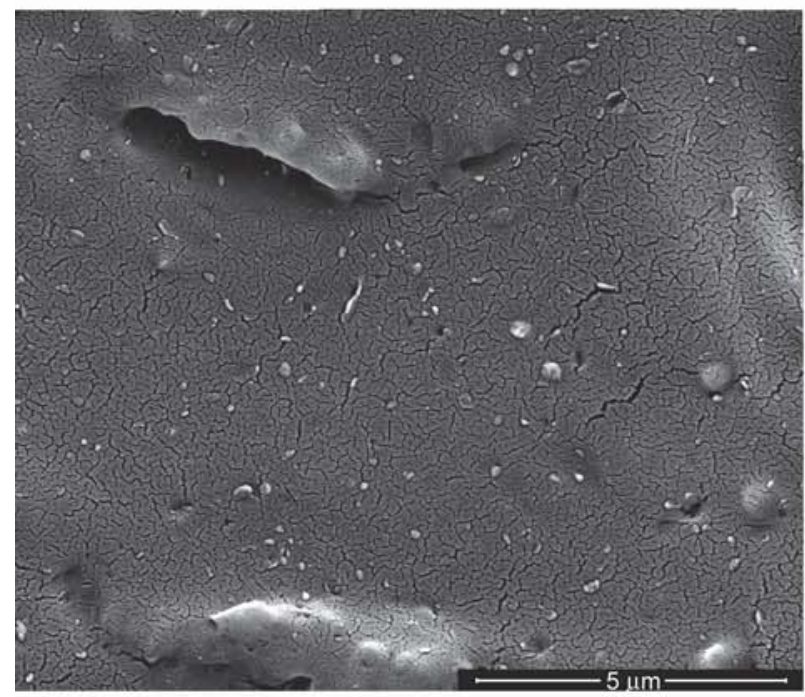

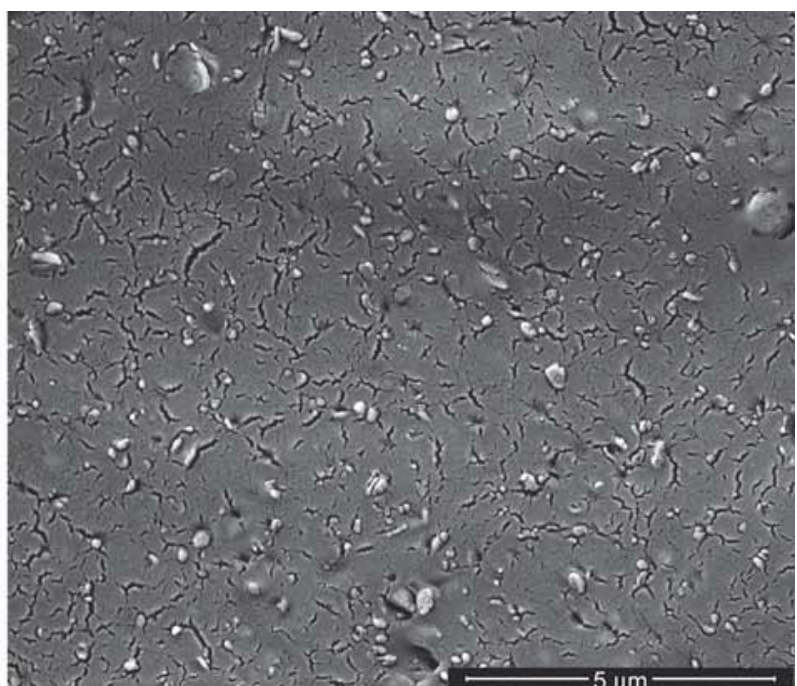

b)

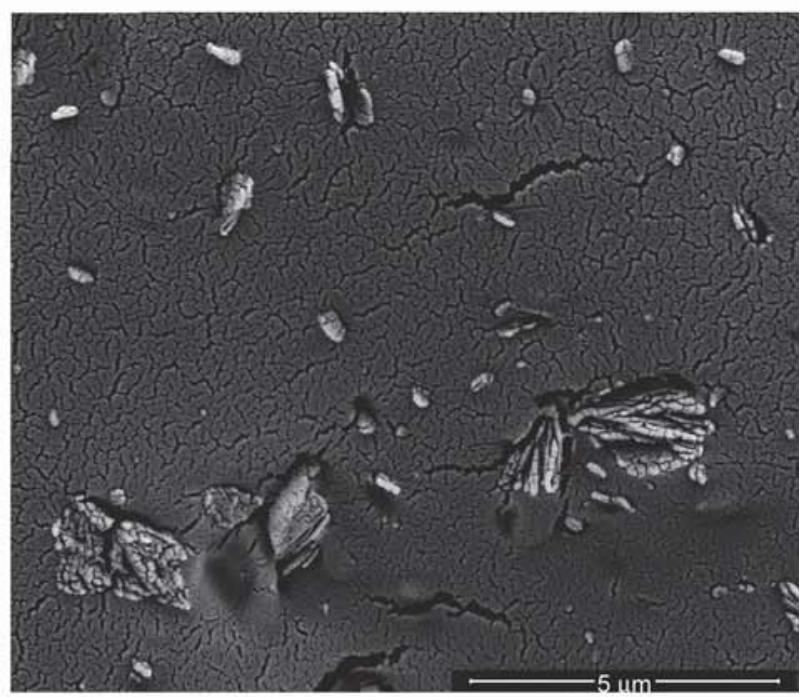

d)

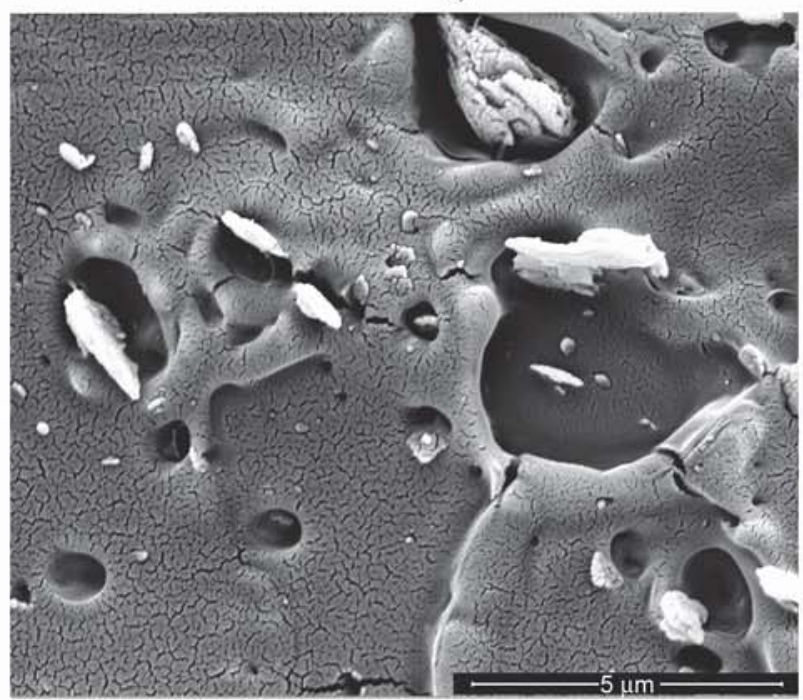

e)

Figure 1. SEM micrographs of (a) PLA + OM-HT R0, (b) PLA + OM-HT R1, (c) PLA + OM-HT R5, (d) PLA + U-HT R0 and (e) PLA + U-HT R5. Scale bars $5 \mu \mathrm{m}$

that lead to a larger contact surface promoting the degradation of PLA.
In order to verify the decrease of molecular weight due to degradation phenomena, intrinsic viscosity 

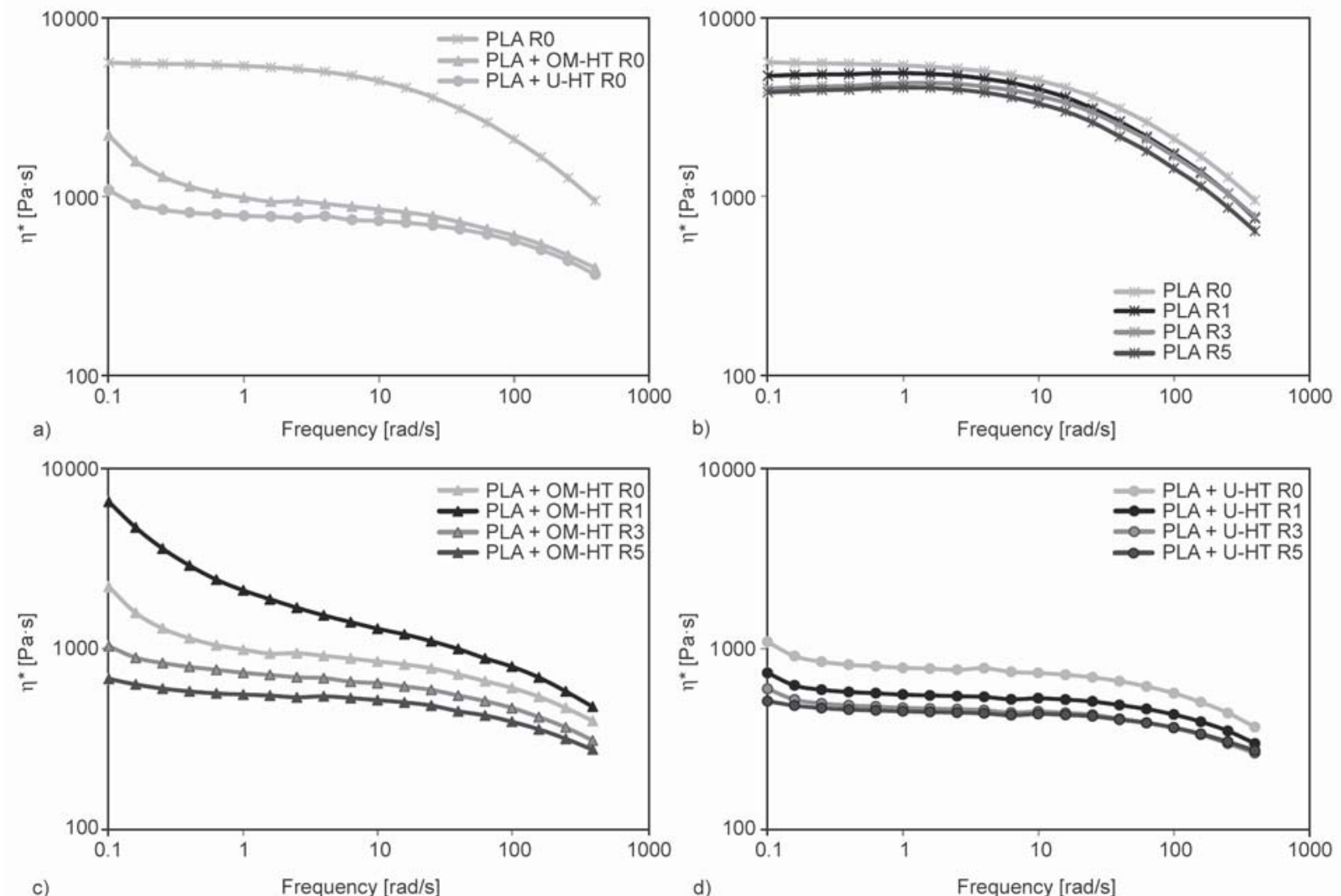

c)

Frequency [rad/s]

d)

Figure 2. Complex viscosity as a function of frequency of (a) the three R0 materials and (b) PLA, (c) PLA + OM-HT and
(d) PLA + U-HT underwent to recycling (d) PLA + U-HT underwent to recycling

measurements were performed (Figure 3). Viscous molar mass $\left(M_{\mathrm{v}}\right)$ as a function of reprocessing cycles is shown in Figure 3a. The results show that the presence of both hydrotalcites causes an strong decrease of $M_{\mathrm{V}}$ even for not reprocessed materials [27]. Moreover, for each reprocessing, nanocomposites exhibit a molecular weight lower than that of the matrix. The result of neat PLA indicates that the structure withstands to thermo-mechanical degradation in the first recycling (Figure 3a). After five reprocessing cycles, the largest decrease is $37 \%$ for PLA + OM-HT from $\mathrm{R} 0$ to R5. The value is comparable with PLA + UHT sample and significantly higher than that observed for the matrix.

In Figure 3b, where the dimensionless values of $M_{\mathrm{v}}$ are plotted, it can be seen that during the reprocessing the rate of decrease of $M_{\mathrm{v}}$ of nanocomposites is higher than that of PLA. Moreover, the rate of decrease of $M_{\mathrm{v}}$ of PLA + OM-HT is higher than that $\mathrm{PLA}+\mathrm{U}-\mathrm{HT}$. This result is probably due to the presence of the organic modifier that could promote the degradation phenomena, as reported in the scientific literature [42].

Results derived from DSC measurements are summarized in Table 2. The $T_{\mathrm{g}}$ of all nanocomposites
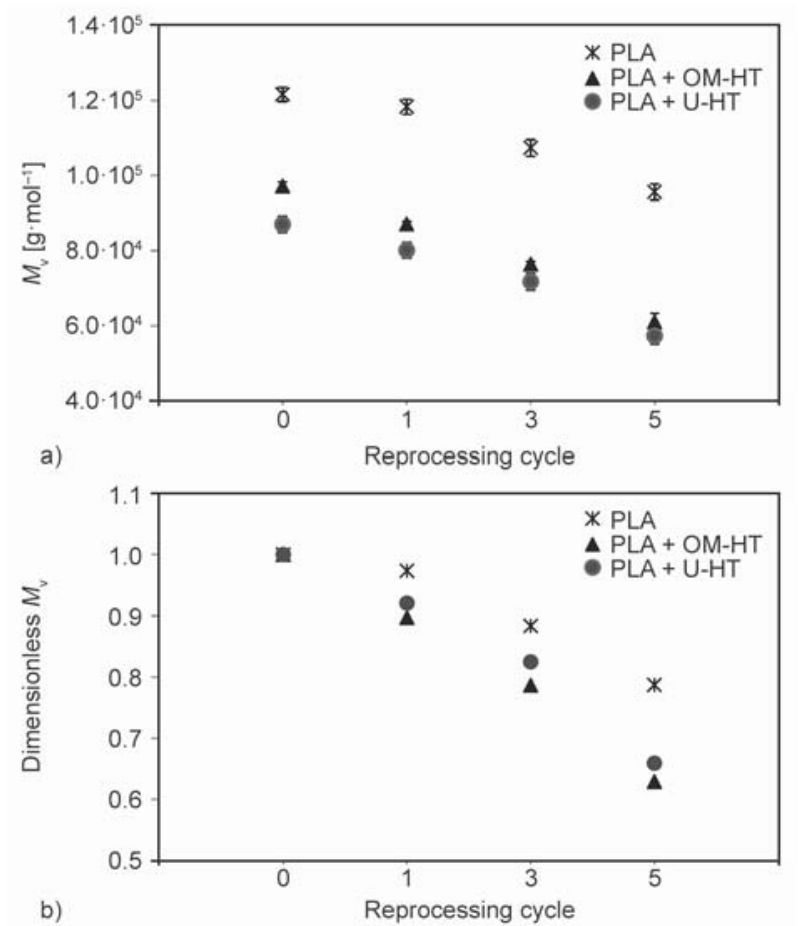

Figure 3. Variation of (a) viscous molar mass and (b) dimensionless viscous molar mass throughout the reprocessing steps. Dimensionless values have been calculated by dividing the value of each recycle by the value of the ' 0 ' recycle. 
Table 2. DSC results of neat PLA, PLA + OM-HT and PLA + U-HT for each extrusion cycle studied

\begin{tabular}{|l|c|c|c|c|c|c|c|}
\hline \multicolumn{1}{|c|}{ Sample } & $\begin{array}{c}\boldsymbol{T}_{\mathbf{g}} \\
{\left[{ }^{\circ} \mathbf{C}\right]}\end{array}$ & $\begin{array}{c}\boldsymbol{T}_{\mathbf{c c}} \\
{\left[{ }^{\circ} \mathbf{C}\right]}\end{array}$ & $\begin{array}{c}\boldsymbol{T}_{\mathbf{m} 1} \\
{\left[{ }^{\circ} \mathbf{C}\right]}\end{array}$ & $\begin{array}{c}\boldsymbol{T}_{\mathbf{m} 2} \\
{\left[{ }^{\circ} \mathbf{C}\right]}\end{array}$ & $\begin{array}{c}\Delta \boldsymbol{H}_{\mathbf{c c}} \\
{[\mathbf{J} \cdot \mathbf{g}-\mathbf{1}]}\end{array}$ & $\begin{array}{c}\Delta \boldsymbol{H}_{\mathbf{m}} \\
{[\mathbf{J} \cdot \mathbf{g}-\mathbf{1}]}\end{array}$ & $\begin{array}{c}\boldsymbol{\chi} \\
{[\mathbf{\%}]}\end{array}$ \\
\hline PLA R0 & 60.2 & 110.9 & 161.9 & 167.9 & 29.2 & 32.6 & 3.6 \\
\hline PLA R1 & 60.5 & 109.7 & 161.5 & 168.2 & 29.1 & 33.0 & 4.1 \\
\hline PLA R3 & 60.5 & 107.4 & 160.7 & 168.2 & 27.8 & 32.0 & 4.5 \\
\hline PLA R5 & 60.2 & 106.2 & 160.2 & 167.7 & 27.6 & 32.1 & 4.8 \\
\hline PLA + OM-HT R0 & 59.5 & 107.5 & 160.2 & 167.0 & 33.5 & 38.8 & 5.7 \\
\hline PLA + OM-HT R1 & 59.5 & 96.9 & - & 166.5 & 32.0 & 38.0 & 6.4 \\
\hline PLA + OM-HT R3 & 59.0 & 96.7 & - & 165.5 & 31.5 & 38.6 & 7.6 \\
\hline PLA + OM-HT R5 & 58.7 & 96.5 & - & 164.9 & 30.8 & 39.1 & 8.9 \\
\hline PLA + U-HT R0 & 59.5 & 110.0 & 161.4 & 168.5 & 34.2 & 38.6 & 4.7 \\
\hline PLA+ U-HT R1 & 59.7 & 108.4 & 160.9 & 168.4 & 31.8 & 37.6 & 6.1 \\
\hline PLA + U-HT R3 & 59.4 & 107.4 & 160.4 & 167.9 & 33.0 & 39.1 & 6.5 \\
\hline PLA + U-HT R5 & 59.7 & 106.9 & 160.0 & 167.7 & 32.2 & 39.6 & 7.9 \\
\hline
\end{tabular}

and neat PLA are very close. Reprocessing does not influence the PLA Tg temperatures, which are in the ranges of $60.2-60.5^{\circ} \mathrm{C}$. For nanocomposites, a slightly lower $T_{\mathrm{g}}$ is observed, which may be related to an increase of free volume, resulting in the presence of more end chains further confirming molar mass reduction, due to an enlarged thermo-mechanical degradation promoted by hydrotalcites.

Cold crystallization is observed for both neat PLA and PLA + HTs samples. Regarding the cold crystallization temperature $\left(T_{\mathrm{cc}}\right)$, a progressive decrease is shown on increasing the extrusion number, in agreement with the results obtained for similar systems $[5,6]$. For neat PLA and PLA + U-HT the decrease is comparable while it is more remarkable for PLA + OM-HT likely due to the better dispersion of OM-HT that promotes an easier cold-crystallization. Moreover, an increment in $\Delta H_{\mathrm{cc}}$ is found from matrix to nanocomposites and the same trend is found for $\Delta H_{\mathrm{m}}$.

PLA matrix shows two melting peaks with the dominant peak at the higher temperature. Other studies have observed similar melting behavior for PLA and its nanocomposites $[4,43]$. The double peak is explained in different ways [33]: (a) formation of a disordered alpha phase of PLA owing to the low crystallization temperature, (b) nucleation of more than one crystal structure and (c) different morphology of the lamellae formed prior to the heating process. Increasing the number of extrusions, the shape of the endotherms changes from a bimodal to an unimodal distribution, which might be attributed to the homogenization of crystals type and size dependant on chain shortening of the PLA [44, 45]. In PLA + OM-HT samples bimodal distribution disappears after the first recycle.
The crystallinity increases on increasing the recycling number and this effect is larger for the filled materials thanks to the synergistic effect played by hydrotalcites as nucleating agent and as promoter of polymer chains shortening easing crystallization kinetics. Indeed, for each extrusion step PLA + OM-HT samples show the highest crystallinity thanks to the better dispersion of modified hydrotalcite.

The effects of reprocessing on the mechanical properties are displayed in Figure 4. Young's modulus $(E)$, tensile strength $(T S)$ and elongation at break $(E B)$ of the nanocomposites are compared with neat PLA. The not reprocessed nanocomposites show a Young's modulus slightly lower than that of the neat matrix processed under the same conditions (Figure 4a). During the subsequent extrusion cycles, the nanocomposites containing U-HT show a trend of mechanical properties comparable to that of PLA matrix, i.e. the elastic modulus increases up to the third recycling, afterwards decreases. These results can likely be attributed to the competition between two phenomena that occurs during reprocessing, i.e. the decrease of molecular weight and the increase of crystallinity that affect in an opposite way the stiffness of the material [41]. On the contrary, the mechanical performance of the material reinforced with OM-HT has a different trend. In particular, the Young's modulus of PLA + OM-HT increases from $1449 \mathrm{MPa}$ in the first recycle to a final value of $1718 \mathrm{MPa}$ in the fifth recycle, increasing by $19 \%$. This behaviour can be explained considering that, although the reprocessing of this system leads to the highest decrease rate of molecular weight, at the same time it improves the morphology of the nanocomposite, i.e. reduction of particle size and higher level of dispersion. Moreover, similarly to the other systems, reprocessing causes a 

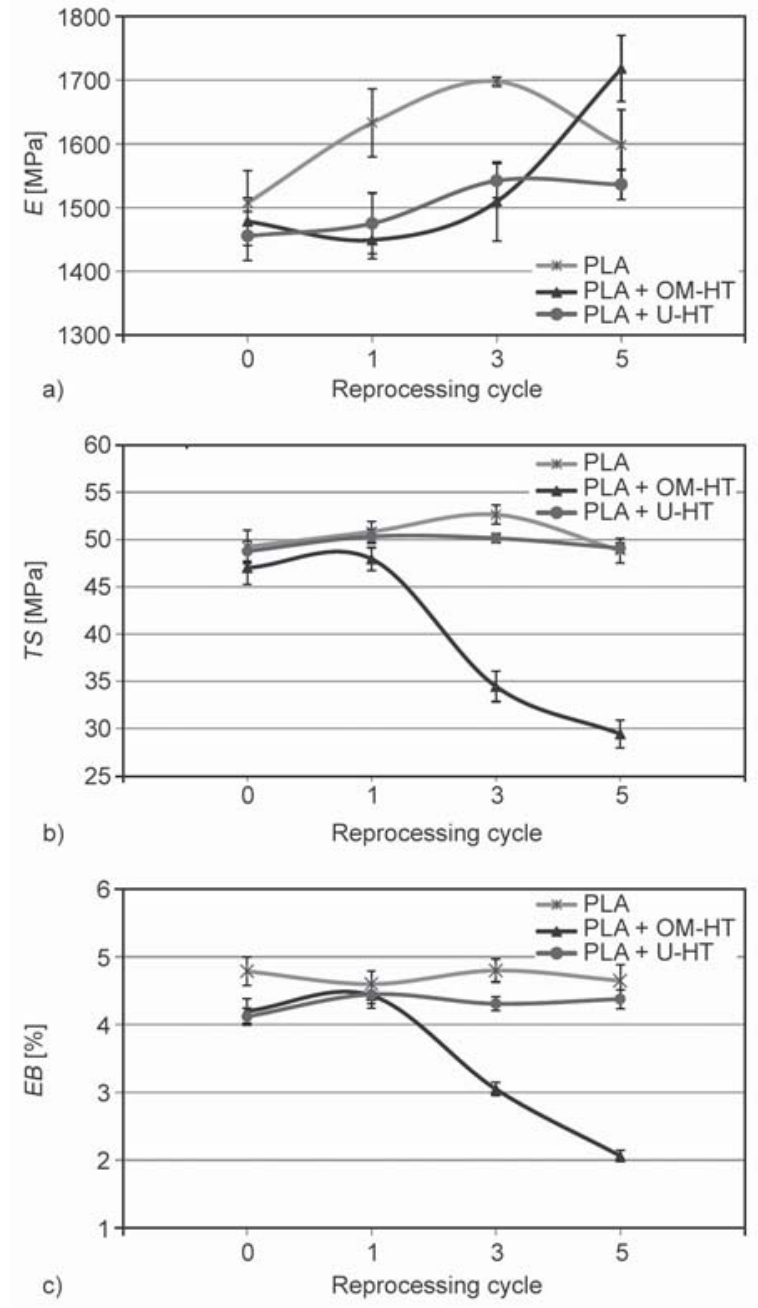

Figure 4. Mechanical properties of neat PLA, PLA + OMHT and PLA + U-HT: (a) Elastic modulus (E), (b) tensile strength (TS) and (c) elongation at break $(E B)$ for the extrusion cycles tested

slight increase of the polymer crystallinity, as already commented. Indeed, the incorporation of OMHT and its dispersion degree cause opposite effects on mechanical behavior leading on the whole to an increase of the stiffness of PLA + OM-HT, as previously reported [27].

Tensile strength of PLA + U-HT remains almost constant during the extrusion cycles, and comparable with the matrix values (Figure 4b) although these latter exhibit a maximum after the third reprocessing. Moreover, the reprocessing cycles do not significantly influence the $E B$ of PLA and of nanocomposite system containing U-HT since even the not reprocessed materials show a brittle behaviour (Figure 4c).

On the contrary, for PLA + OM-HT samples, both properties at break, i.e. $T S$ and $E B$, exhibit a drop after the first recycling, showing in both cases, the same trend observed for the elastic modulus. Indeed, as commented before, phenomena occurring during the reprocessing of the system containing the OMHT, i.e. decreasing of the molecular weight, improvement of the morphology and increment of the crystallinity leading, on the whole, to an increase of the stiffness of PLA + OM-HT, decreases the sample ductility.

\section{Conclusions}

The effects of reprocessing on molecular structure, morphology and properties of melt reprocessed PLA/ hydrotalcites nanocomposites were studied after five subsequent extrusion cycles.

The investigations highlighted opposite effects, i.e. nanofiller dispersion, crystallinity, viscous molar mass, that affect the properties in melt, in solution and in solid.

The morphological analysis revealed that the materials containing modified hydrotalcite show the higher degree of dispersion and adhesion in comparison with those containing unmodified hydrotalcite. By reprocessing OM-HT becomes smaller and more finely dispersed in the PLA matrix. This result justifies the rheological and mechanical measurements during the first few reprocessing cycle. In the subsequent recycles, reduction in complex viscosity indicates that the occurrence of chain scission overcomes nanofiller effect, as confirmed by the mechanical performance. Reprocessing causes a remarkable decrease of viscous molar mass especially in the nanocomposites, as confirmed by viscosimetric molecular weight measurements. Both the hydrotalcites organically modified and unmodified - cause the increase of the thermo-mechanical degradation rate of the matrix. The hydrotalcites lead to an increase of the crystallinity of the materials suggesting the double effect due to the nanofiller incorporation, as nucleating agent and as promoters of the chain shortening.

\section{References}

[1] Yin S., Tuladhar R., Shi F., Shanks R. A., Combe M., Collister T.: Mechanical reprocessing of polyolefin waste: A review. Polymer Engineering and Science, 55, 2899-2909 (2015).

https://doi.org/10.1002/pen.24182

[2] Scaffaro R., Botta L., Di Benedetto G.: Physical properties of virgin-recycled ABS blends: Effect of postconsumer content and of reprocessing cycles. European Polymer Journal, 48, 637-648 (2012).

https://doi.org/10.1016/j.eurpolymj.2011.12.018 
[3] Luckachan G. E., Pillai C. K. S.: Biodegradable polymers - A review on recent trends and emerging perspectives. Journal of Polymers and the Environment, 19, 637-676 (2011).

https://doi.org/10.1007/s10924-011-0317-1

[4] Fiore V., Botta L., Scaffaro R., Valenza A., Pirrotta A.: PLA based biocomposites reinforced with Arundo donax fillers. Composites Science and Technology, 105, 110 117 (2014).

https://doi.org/10.1016/j.compscitech.2014.10.005

[5] Badia J. D., Strömberg E., Karlsson S., Ribes-Greus A.: Material valorisation of amorphous polylactide. Influence of thermo-mechanical degradation on the morphology, segmental dynamics, thermal and mechanical performance. Polymer Degradation and Stability, 97, 670-678 (2012).

https://doi.org/10.1016/j.polymdegradstab.2011.12.019

[6] Żenkiewicz M., Richert J., Rytlewski P., Moraczewski K., Stepczyńska M., Karasiewicz T.: Characterisation of multi-extruded poly(lactic acid). Polymer Testing, 28, 412-418 (2009). https://doi.org/10.1016/j.polymertesting.2009.01.012

[7] Peinado V., Castell P., García L., Fernández A.: Effect of extrusion on the mechanical and rheological properties of a reinforced poly(lactic acid): Reprocessing and recycling of biobased materials. Materials, 8, 7106-7117 (2015).

https://doi.org/10.3390/ma8105360

[8] Scaffaro R., Morreale M., Mirabella F., La Mantia F. P.: Preparation and recycling of plasticized PLA. Macromolecular Materials and Engineering, 296, 141-150 (2011). https://doi.org/10.1002/mame.201000221

[9] Morreale M., Liga A., Mistretta M. C., Ascione L., La Mantia F. P.: Mechanical, thermomechanical and reprocessing behavior of green composites from biodegradable polymer and wood flour. Materials, 8, 7536-7548 (2015). https://doi.org/10.3390/ma8115406

[10] La Mantia F. P., Botta L., Morreale M., Scaffaro R.: Effect of small amounts of poly(lactic acid) on the recycling of poly(ethylene terephthalate) bottles. Polymer Degradation and Stability, 97, 21-24 (2012). https://doi.org/10.1016/j.polymdegradstab.2011.10.017

[11] La Mantia F. P., Scaffaro R., Bastioli C.: Recycling of a starch-based biodegradable polymer. Macromolecular Symposia, 180, 133-140 (2002)

https://doi.org/10.1002/15213900(200203)180:1\%3C133::aid-masy133\%3E3.0.co;2-9

[12] Al-Salem S. M., Lettieri P., Baeyens J.: Recycling and recovery routes of plastic solid waste (PSW): A review. Waste Management, 29, 2625-2643 (2009). https://doi.org/10.1016/j.wasman.2009.06.004

[13] La Mantia F. P., Mistretta M. C., Morreale M.: Recycling and thermomechanical degradation of LDPE/modified clay nanocomposites. Macromolecular Materials and Engineering, 299, 96-103 (2014).

https://doi.org/10.1002/mame.201200449
[14] Scaffaro R., Botta L., La Mantia F. P.: Preparation and characterization of polyolefin-based nanocomposite blown films for agricultural applications. Macromolecular Materials and Engineering, 294, 445-454 (2009). https://doi.org/10.1002/mame.200900004

[15] Scaffaro R., Botta L., Mistretta M. C., La Mantia F. P.: Preparation and characterization of polyamide 6/polyethylene blend-clay nanocomposites in the presence of compatibilisers and stabilizing system. Polymer Degradation and Stability, 95, 2547-2554 (2010). https://doi.org/10.1016/j.polymdegradstab.2010.07.029

[16] Delva L., Ragaert K., Degrieck J., Cardon L.: The effect of multiple extrusions on the properties of montmorillonite filled polypropylene. Polymers, 6, 2912-2927 (2014). https://doi.org/10.3390/polym6122912

[17] Peres A. M., Pires R. R., Oréfice R. L.: Evaluation of the effect of reprocessing on the structure and properties of low density polyethylene/thermoplastic starch blends. Carbohydrate Polymers, 136, 210-215 (2016). https://doi.org/10.1016/j.carbpol.2015.09.047

[18] Touati N., Kaci M., Bruzaud S., Grohens Y.: The effects of reprocessing cycles on the structure and properties of isotactic polypropylene/Cloisite 15A nanocomposites. Polymer Degradation and Stability, 96, 1064-1073 (2011). https://doi.org/10.1016/j.polymdegradstab.2011.03.015

[19] Remili C., Kaci M., Benhamida A., Bruzaud S., Grohens Y.: The effects of reprocessing cycles on the structure and properties of polystyrene/Cloisite 15A nanocomposites. Polymer Degradation and Stability, 96, 1489-1496 (2011). https://doi.org/10.1016/j.polymdegradstab.2011.05.005

[20] Amorin N. S. Q. S., Rosa G., Alves J. F., Gonçalves S. P. C., Franchetti S. M. M., Fechine G. J. M.: Study of thermodegradation and thermostabilization of poly(lactide acid) using subsequent extrusion cycles. Journal of Applied Polymer Science, 131, 40023/1-40023/8 (2014). https://doi.org/10.1002/app.40023

[21] Rojas Gonzalez A. F., Carrero Mantilla J. I.: Thermal degradation kinetic of polylactic acid in multiple extrusions. Ingenieria Y Universidad, 19, 189-206 (2015). https://doi.org/10.11144/javeriana.iyu19-1.tdkp

[22] Nascimento L., Gamez-Perez J., Santana O. O., Velasco J. I., Maspoch M. L., Franco-Urquiza E.: Effect of the recycling and annealing on the mechanical and fracture properties of poly(lactic acid). Journal of Polymers and the Environment, 18, 654-660 (2010). https://doi.org/10.1007/s10924-010-0229-5

[23] Zhou Q., Xanthos M.: Nanoclay and crystallinity effects on the hydrolytic degradation of polylactides. Polymer Degradation and Stability, 93, 1450-1459 (2008). https://doi.org/10.1016/j.polymdegradstab.2008.05.014

[24] Trifol J., Plackett D., Sillard C., Szabo P., Bras J., Daugaard A. E.: Hybrid poly(lactic acid)/nanocellulose/nanoclay composites with synergistically enhanced barrier properties and improved thermomechanical resistance. Polymer International, 65, 988-995 (2016). https://doi.org/10.1002/pi.5154 
[25] Ha J. U., Xanthos M.: Novel modifiers for layered double hydroxides and their effects on the properties of polylactic acid composites. Applied Clay Science, 47, 303-310 (2010). https://doi.org/10.1016/j.clay.2009.11.033

[26] Coiai S., Cicogna F., de Santi A., Pérez Amaro L., Spiniello R., Signori F., Fiori S., Oberhauser W., Passaglia E.: MMT and LDH organo-modification with surfactants tailored for PLA nanocomposites. Express Polymer Letters, 11, 163-175 (2017).

https://doi.org/10.3144/expresspolymlett.2017.18

[27] Scaffaro R., Botta L., Passaglia E., Oberhauser W., Frediani M., Di Landro L.: Comparison of different processing methods to prepare poly(lactid acid)-hydrotalcite composites. Polymer Engineering and Science, 54, 1804-1810 (2014). https://doi.org/10.1002/pen.23724

[28] Gerds N., Katiyar V., Koch C. B., Hansen H. C. B., Plackett D., Larsen E. H., Risbo J.: Degradation of Lpolylactide during melt processing with layered double hydroxides. Polymer Degradation and Stability, 97, 2002-2009 (2012).

https://doi.org/10.1016/j.polymdegradstab.2012.04.014

[29] Leng J., Purohit P. J., Kang N., Wang D-Y., Falkenhagen J., Emmerling F., Thünemann A. F., Schönhals A.: Structure-property relationships of nanocomposites based on polylactide and $\mathrm{MgAl}$ layered double hydroxides. European Polymer Journal, 68, 338-354 (2015).

https://doi.org/10.1016/j.eurpolymj.2015.05.008

[30] Demirkaya Z. D., Sengul B., Eroglu M. S., Dilsiz N.: Comprehensive characterization of polylactide-layered double hydroxides nanocomposites as packaging materials. Journal of Polymer Research, 22, 124/1-124/13 (2015).

https://doi.org/10.1007/s10965-015-0759-6

[31] Chiang M-F., Wu T-M.: Synthesis and characterization of biodegradable poly(L-lactide)/layered double hydroxide nanocomposites. Composites Science and Technology, 70, 110-115 (2010).

https://doi.org/10.1016/j.compscitech.2009.09.012

[32] Coiai S., Scatto M., Conzatti L., Azzurri F., Andreotti L., Salmini E., Stagnaro P., Zanolin A., Cicogna F., Passaglia E.: Optimization of organo-layered double hydroxide dispersion in LDPE-based nanocomposites. Polymers for Advanced Technologies, 22, 2285-2294 (2011). https://doi.org/10.1002/pat.1759

[33] Du Y., Wu T., Yan N., Kortschot M. T., Farnood R.: Fabrication and characterization of fully biodegradable natural fiber-reinforced poly(lactic acid) composites. Composites Part B: Engineering, 56, 717-723 (2014). https://doi.org/10.1016/j.compositesb.2013.09.012

[34] Abdel-Azim A-A. A., Atta A. M., Farahat M. S., Boutros W. Y.: Determination of intrinsic viscosity of polymeric compounds through a single specific viscosity measurement. Polymer, 39, 6827-6833 (1998).

https://oi.org/10.1016/s0032-3861(98)00184-0
[35] Dorgan J. R., Janzen J., Knauss D. M., Hait S. B., Limoges B. R., Hutchinson M. H.: Fundamental solution and single-chain properties of polylactides. Journal of Polymer Science Part B: Polymer Physics, 43, 3100--3111 (2005).

https://doi.org/10.1002/polb.20577

[36] Malinowski R.: Effect of high energy $\beta$-radiation and addition of triallyl isocyanurate on the selected properties of polylactide. Nuclear Instruments and Methods in Physics Research Section B: Beam Interactions with Materials and Atoms, 377, 59-66 (2016). https://doi.org/10.1016/j.nimb.2016.04.028

[37] Gu S-Y., Ren J., Wang Q-F.: Rheology of poly(propylene)/clay nanocomposites. Journal of Applied Polymer Science, 91, 2427-2434 (2004). https://doi.org/10.1002/app.13403

[38] Bagheriasl D., Carreau P. J., Riedl B., Dubois C., Hamad W. Y.: Shear rheology of polylactide (PLA)-cellulose nanocrystal (CNC) nanocomposites. Cellulose, 23, 18851897 (2016). https://doi.org/10.1007/s10570-016-0914-1

[39] La Mantia F. P., Mistretta M. C., Palermo S., Koci E., Ceraulo M.: Thermomechanical degradation of PLAbased nanobiocomposite. Polymers for Advanced Technologies, 27, 308-313 (2016).

https://doi.org/10.1002/pat.3637

[40] Scaffaro R., Morreale M., Lo Re G., La Mantia F. P.: Effect of the processing techniques on the properties of ecocomposites based on vegetable oil-derived Mater$\mathrm{Bi}^{\circledR}$ and wood flour. Journal of Applied Polymer Science, 114, 2855-2863 (2009). https://doi.org/10.1002/app.30822

[41] Pillin I., Montrelay N., Bourmaud A., Grohens Y.: Effect of thermo-mechanical cycles on the physico-chemical properties of poly(lactic acid). Polymer Degradation and Stability, 93, 321-328 (2008).

https://doi.org/10.1016/j.polymdegradstab.2007.12.005

[42] Scaffaro R., Botta L., Ceraulo M., La Mantia F. P.: Effect of kind and content of organo-modified clay on properties of PET nanocomposites. Journal of Applied Polymer Science, 122, 384-392 (2011).

https://doi.org/10.1002/app.34087

[43] Pantani R., De Santis F., Sorrentino A., De Maio F., Titomanlio G.: Crystallization kinetics of virgin and processed poly(lactic acid). Polymer Degradation and Stability, 95, 1148-1159 (2010).

https://doi.org/10.1016/j.polymdegradstab.2010.04.018

[44] Yasuniwa M., Tsubakihara S., Sugimoto Y., Nakafuku C.: Thermal analysis of the double-melting behavior of poly(L-lactic acid). Journal of Polymer Science Part B: Polymer Physics, 42, 25-32 (2004). https://doi.org/10.1002/polb.10674

[45] Pan P., Kai W., Zhu B., Dong T., Inoue Y.: Polymorphous crystallization and multiple melting behavior of poly(L-lactide): Molecular weight dependence. Macromolecules, 40, 6898-6905 (2007). https://doi.org/10.1021/ma071258d 